\title{
Comparison of Primary Hip Spica with Crossed Retrograde Intramedullary Rush Pins for the Management of Diaphyseal Femur Fractures in Children: A Prospective, Randomized Study
}

\author{
Mohammad Ruhullah ${ }^{1 *}$, Sanjay Shah ${ }^{1}$, Hare Ram Singh ${ }^{1}$, Dipak Shrestha ${ }^{2}$ \\ ${ }^{1}$ National Medical College, Orthopaedics, Birgunj, Narayani 97751, Nepal; ${ }^{2}$ Dhulikhel Hospital, Orthopaedics, Dhulikhel, \\ Bagmati, Nepal
}

\author{
Citation: Ruhullah $M$, Shah S, Singh HR, \\ Shrestha D. Comparison of Primary Hip Spica \\ with Crossed Retrograde Intramedullary Rush \\ Pins for the Management of Diaphyseal Femur \\ Fractures in Children: A Prospective \\ Randomized Study. OA Maced J Med Sci. 2013 \\ Dec 15; 1(1):12-17. \\ http://dx.doi.org/10.3889/oamjms.2103.003 \\ Key words: Femoral fractures; Childrens; \\ Close reduction; Hip spica; Rush Pins. \\ "Correspondence: Dr. Mohammad Ruhullah. \\ National Medical College, Orthopaedics, \\ Birguni, Narayani 97751, Nepal. Phone: \\ Birgunj, Narayani 97751 \\ E-Mail: drruhullah@yahoo.com \\ Received: 06-Jun-2013; Revised: 21-Aug- \\ 2013; Accepted: 22-Aug-2013; Online first: \\ 01-Oct-2013 \\ Copyright: () 2013 Ruhullah M. This is an \\ open-access article distributed under the terms \\ of the Creative Commons Attribution License \\ which permits unrestricted use, distribution, \\ and reproduction in any medium, provided the \\ original author and source are credited. \\ Competing Interests: The authors have \\ declared that no competing interests exist.
}

\begin{abstract}
Introduction: Femoral fractures are common in children between 2 and 12 years of age, and $75 \%$ of the lesions affect the femoral shaft. We compared primary hip spica with closed reduction and fixation with retrogradely crossed Rush pins for diaphyseal femur fracture in 25 children of age group 3 to 13 years randomly distributed in each group.
\end{abstract}

Methods: Fifty children with femoral fractures were evaluated; 25 of them underwent conservative treatment using immediate hip spica (group A) and 25 were treated with crossed retrograde Rush pins (group B). The patients ages ranged from 3 to 13 years (mean age $5.6 \pm 3.57$ yrs).

Results: Mean clinico-radiological consolidation was within 15 weeks in group A and 12 weeks in group B. Mean duration of weight bearing 7 weeks in group B and 14 weeks in group A. Mean hospital stay were 8 days in group B and 4 days in group A. Mean follow up period in group A was 16 months and group $B$ was 17 months. Complications like angulation, shortening, infection were compared. Bursitis and penetration of pins at the site of Rush pin insertion is complication associated with this method of treatment.

Conclusions: Intra-medullary crossed Rush pinning is an effective method of paediatric diaphyseal femur fracture fixation as compared to primary hip spica in terms of early weight bearing and restoration of normal anatomy.

\section{Introduction}

Femoral shaft fractures are one of the commonest fractures of lower extremity in children and the commonest requiring hospital admission. Variety of methods are used for treatment of paediatric diaphyseal femur fractures including immediate spica casting, traction followed by spica casting, external fixators, osteosynthesis with plate, internal fixation with intramedullary rod or flexible intreamedullary nail. Choice of treatment depends upon age of children, anatomical site, and fracture pattern and preference of the surgeon also. Traditionally children below 6 yrs are treated with immediate hip spica and adolescent children are treated with operative methods [1-3].

External fixators are associated with increased chances of pin tract infection and refracture. Plate osteosynthesis need extensive soft tissue strapping and resurgery for removal. Intramedullary rods increase chances of avascular necrosis of femoral head and damage to physis. Flexible intramedullary nailing has become an increasingly popular method of paediatric femoral fracture fixation $[4,5]$. Systemic reviews and various cohort studies have shown excellent clinical results with flexible intramedullary nails (Rush pins) for children and few 
studies has extended its indication to pre school going children also. But no randomized controlled trial has been reported comparing flexible intramedullary Rush nailing with other mode of management of paediatric diaphyseal femur fracture.

We present a randomized controlled trial comparing flexile intramedullary Rush pins with immediate spica casting for paediatric diaphyseal femur fracture.

\section{Materials and Methods}

Fifty children of age group 3 to $13 \mathrm{yrs}$ presenting to Teaching Hospital of National Medical College (Nov 2010 to Dec 2012) with diaphyseal femur fracture were randomly allocated into group $A$ (Immediate hip spica casting) and group B (Flexible intramedullary Rush pins) with random number generation technique.

Inclusion criteria for selection of both groups patient were: (a) diaphyseal femoral fracture of age group 3 to 13 yrs; (b) displaced fractures, with or without comminution; (c) multiple fractures; and (d) fractures in patients with polytrauma.

Exclusion criteria for selection of both groups patient were: (a) undisplaced fractures and fractures in a good position were treated by traction and hip spica; (b) pathological fracture; (c) compound fracture; (d) children with neuromuscular disorders, metabolic bone disorders; (e) irritable patients with brain injury; (e) associated vascular injury needing repair.
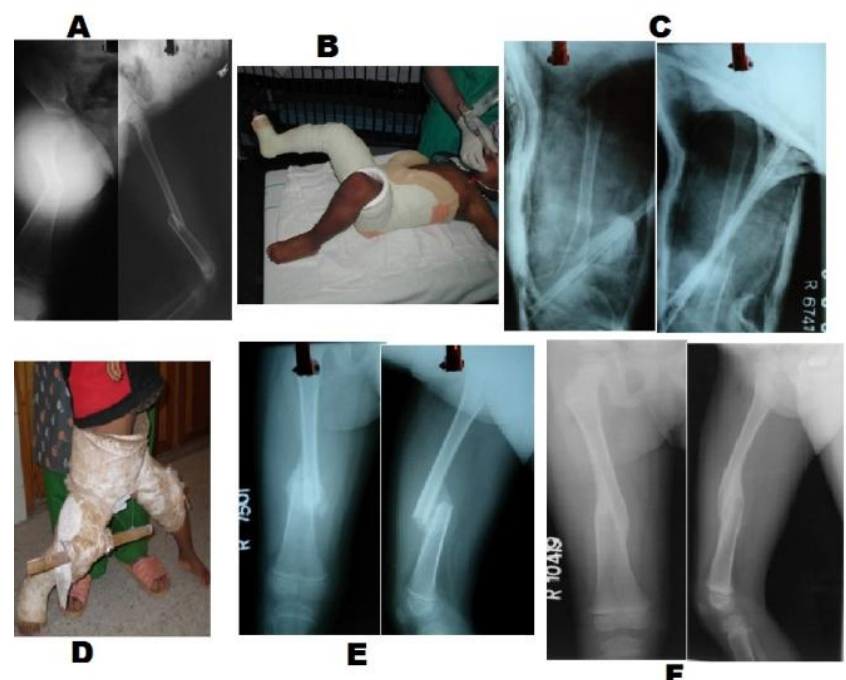

Figure 1: Children with femoral shaft fractures; before hip spica $x$ ray $(A)$, in spica cast $(B)$, after the cast $(C)$, Broken spica on 6th week follow up $(D), x$-ray on 6th week follow up $(E)$ and final $x$-ray at 4th month follow up $(F)$.

In group $A$, fracture was reduced on the same day or next day of presentation to hospital with fluoroscopy control one and half hip spica cast were applied under general anesthesia, traction applied on fracture limb, hip flexed at between 30 - 45 degrees with semi-flexion of the knee while ankle in neutral position (Figure 1). Criteria of acceptable reduction were based upon Kasser et al (Table 1). Children were admitted to hospital until parents learned how to take care of spica. Follow up was performed at $2^{\text {nd }}$ week for evaluation of reduction and spica related complications. Radiological evaluation of bridging callus was performed at $6^{\text {th }}$ week for evaluation of radiological union. If bridging callus was seen at three cortices, child was asked to bear weight with or without support according to pain tolerance. If callus was not evident long leg cast was applied for 4 more weeks.

Table 1: Criteria of acceptable reduction (Kasser JR, Beaty JH).

\begin{tabular}{|c|c|c|c|}
\hline $\mathrm{Ast}$ & 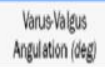 & 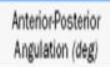 & Shontening (MMI) \\
\hline $6.10 y$ & 10 & 15 & 15 \\
\hline 11 y to maturity & 5 & 10 & 10 \\
\hline
\end{tabular}

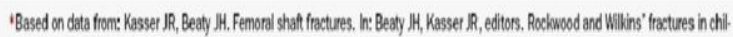
deen. 5th ed. Philadelphis: Lippincot Willians and Wikins; 2001. p 948.

In group B, under general anaesthesia, two small skin incisions were made on either side of distal metaphysis and two holes are made obliquely facing towards medullary cavity with help of $4 \mathrm{~mm}$ awl, an inch proximal to growth plate. Two pre contoured Cshaped Rush pins were passed retrogradely with fluoroscopy control till both the tips reached just distal to fracture site. Fracture was reduced with manual traction and rush pins are pushed into medullary cavity of proximal fragment under fluoroscopy control (Figure 2). Tips of the pins are targeted up to the level of neck and base of the greater trochanter. Care was taken that bent distal part of rush pin lied on cortical surface of the supracondylar of femur without soft tissue was impingement. Size of the Rush pins were measured as $40 \%$ of narrowest diameter of femur on anteroposterior and lateral view.

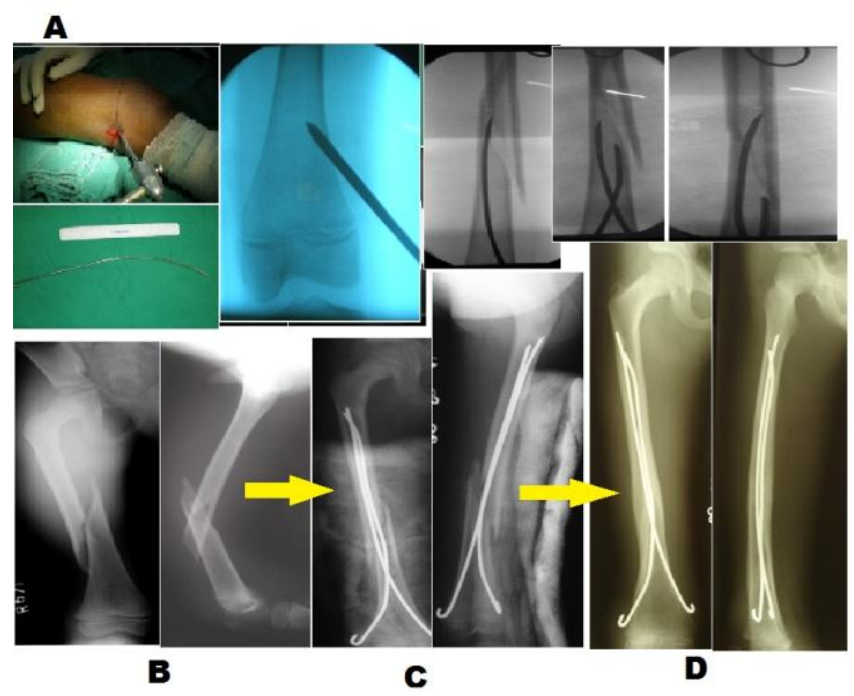

Figure 2: Fixation of flexible intramedullary Rush Pins procedure in a child with femoral shaft fracture $(A)$ and radiographs taken pre op $(B)$, immediate post op $(C)$ and finally at 14 month follow op (D). 
In initial few comminuted fracture cases we applied posterior long leg plaster of Paris back slab toe-to-thigh (above knee) which we later discontinued till sutures were removed at 2 weeks. As soon as pain was tolerable, hip and knee range of motion with quadriceps muscle strengthening exercise was started and non weight bearing ambulation was allowed. Weight bearing was permitted once bridging callus is evident on X- ray on three cortices. Follow up was done at 6 weeks, 12 weeks, 6 months, 1 year and 2 years for radiological and clinical evaluation (Figure 3).

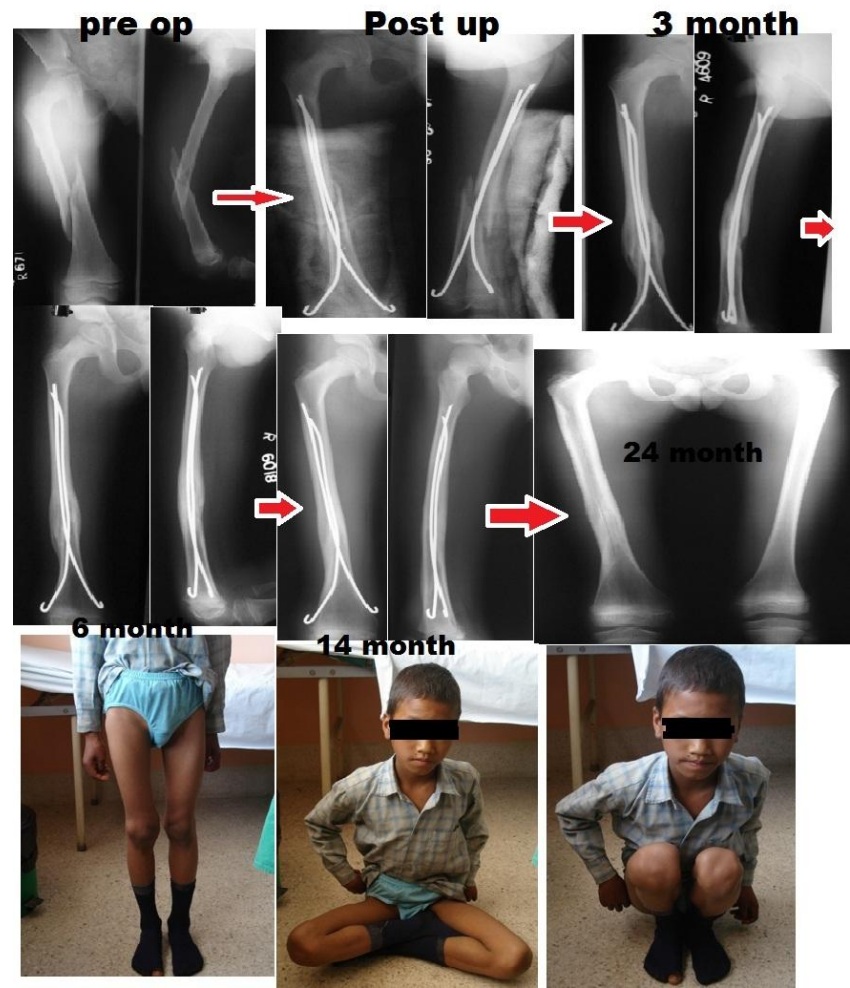

Figure 3: Radiological and Clinical evaluation outcome of Rush pin fixation.

Rush pins were routinely removed after one year of surgery. Treatment cost was calculated as total amount paid to hospital which covered admission; investigation, operation and hospital stay charges because many indirect costs associated with total management which could not be generalized.

\section{Statistical analysis}

Success of randomization was tested between two groups. Magnitude of difference between two groups was measured between means in both group by SPSS 11.5 software and significance of difference was measured by determining $p$ value using Chi square test for qualitative variables and for quantitative variable by independent $t$ test or Mann Whitney $U$ test depending upon whether $p$ value obtained from Kolmogorov--Smirnov $Z$ test for homogeneity of variance was below or above 0.05 . $P$ value $<0.05$ considered as statistically significant.

\section{Results}

Table 2 shows success of randomization between two groups in terms of age, sex, weight, side, fracture pattern, stability, mode of injury and anatomical site.

Table 2: Showing success of randomization.

\begin{tabular}{|c|c|c|c|}
\hline Variables & $\begin{array}{l}\text { Group A (Hip spica) } \\
(\mathrm{N}-25)\end{array}$ & $\begin{array}{l}\text { Group B (Rush pin) } \\
(N=25)\end{array}$ & $\begin{array}{c}P \\
\text { values }\end{array}$ \\
\hline Age (Yrs \pm SD) & $5.6 \pm 3.61$ & $6.92 \pm 3.57$ & 020 \\
\hline \multicolumn{4}{|l|}{ Sex } \\
\hline Male & 18 & 20 & 0.5 \\
\hline Female & 7 & 5 & \\
\hline Weight (Kgs \pm SD) & $17.44 \pm 7.68$ & $20.4+8.29$ & 0.19 \\
\hline \multicolumn{4}{|l|}{ Side } \\
\hline $\begin{array}{l}\text { Right } \\
\text { Left }\end{array}$ & $\begin{array}{l}14 \\
11\end{array}$ & $\begin{array}{c}18 \\
7\end{array}$ & 024 \\
\hline \multicolumn{4}{|l|}{ Classification } \\
\hline 32A1 & 9 & 13 & \\
\hline 32A2 & 4 & 3 & \\
\hline $32 \mathrm{~A} 3$ & 9 & 4 & 0.43 \\
\hline 32B1 & $\mathbf{1}$ & 3 & \\
\hline $32 \mathrm{~B} 2$ & 2 & 2 & \\
\hline \multicolumn{4}{|l|}{ Stability } \\
\hline Unstable & 16 & 20 & 033 \\
\hline $\begin{array}{c}\text { Stable } \\
\text { Mode of injury }\end{array}$ & 9 & 5 & \\
\hline Height & 14 & 11 & \\
\hline $\begin{array}{l}\text { Tree } \\
\text { RTA }\end{array}$ & 4 & 6 & \\
\hline $\begin{array}{l}\text { RTA } \\
\text { Play ground }\end{array}$ & $\begin{array}{l}2 \\
1\end{array}$ & $\begin{array}{l}1 \\
2\end{array}$ & 061 \\
\hline Staircase & 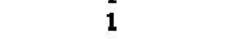 & 3 & \\
\hline Wall & 3 & 1 & \\
\hline Cliff & 0 & 1 & \\
\hline \multicolumn{4}{|l|}{ Fracture site } \\
\hline Proximal & 5 & 4 & \\
\hline Middle & 18 & 20 & 0.76 \\
\hline Distal & 2 & $\mathbf{1}$ & \\
\hline
\end{tabular}

Age in both groups ranged from 3 to 13 years with mean age of $5.6 \pm 3.61$ yrs in group $A$ and $6.92 \pm$ $3.57 \mathrm{yrs}$ in group $B$. Male to female ratio was $2.5: 1$ in group $A$ and $4: 1$ in group $B$ respectively. Fracture pattern was classified according to $\mathrm{AO}$ classification, which showed type $32 \mathrm{~A} 1$, was the most common pattern of injury. Spiral or long oblique fractures or fractures with comminuation more than $2 / 3 \mathrm{rd}$ of diameter of bone were considered unstable. Fall related injury either from hill slope, tree, cliff or wall was commonest mode of injury and comprised of $88 \%$ of injury in each group A and B. Anatomically, femoral diaphysis was most common site of femur fracture in this study.

Mean follow up period in group $A$ was 16.1 months (range 6-26 months) and in group $B$ it was 17 months (range 6 to 28 months). One patient in group A could not followed up after discharging from the hospital and hence excluded from analysis.

\section{Fracture healing and return to normal activity}

Sixteen children of 25 in group B who could be trained for ambulation with walking aids started walking much earlier than 14 children of 24 in group A with significant mean difference (13.38 \pm 2.3 days in group B vs. $52.33 \pm 4.5$ days in group $A, p=0.000$ ). Similarly children in group $B$ started walking without 
aid with mean duration of $6.6 \pm 1.29$ weeks as compare to $10.67 \pm 4.32$ weeks in group $A$. $(p=0.002) .17$ children in group $B$ and 13 in group $A$ were school going children pre operatively. Mean duration of return to school in group $B$ was $8.82 \pm 01.7$ weeks and $15.6 \pm 2.98$ weeks in group $A(p=0.000)$. In group $A$, clinico-radiological union was achieved within 12 weeks duration in 10 cases, in 16 weeks in 12 cases and 17 weeks in 2 cases with mean union time of $13.25 \pm 2.43$ weeks where as all the fractures united within 12 weeks in group $B$ with mean duration of $10.76 \pm 0.72$ weeks $(p=0.000)$. Children returned to full activities at mean time of $8.76 \pm 2.27$ weeks in group $B$ and $12.08 \pm 4.51$ weeks in group $A(p=0.027)$. (Table 3).

Table 3: Outcome variables comparing two groups.

\begin{tabular}{|c|c|c|c|}
\hline Variables & $\begin{array}{c}\text { Group A } \\
\text { (Hi ip spica) } \\
\mathrm{N}=24\end{array}$ & $\begin{array}{c}\text { Group B } \\
(\mathrm{R} \text { ush pin) } \\
\mathrm{N}=25\end{array}$ & Pralues \\
\hline Hospital Stay (days) & $3.32 \pm 1.4$ & $6.56 \pm 2.75$ & 0.0001 \\
\hline Wa lking w ith aids (d ays) & $52.33 \pm 1.55$ & $7.38 \pm 0.68$ & 0.0001 \\
\hline Wa lking w ithout aids (W ks) & $10.6 \pm 0.88$ & $6.6 \pm 0.25$ & 0.0001 \\
\hline Weight bearing (Wks) & $125 \pm 0.41$ & $5.6 \pm 0.22$ & 0.0001 \\
\hline Return to full actin ity (W ks) & $15.6 \pm 0.82$ & $8.8 \pm 0.41$ & 0.0001 \\
\hline Return to school (Wks) & $115 \pm 1.03$ & $8.7 \pm 0.45$ & 0.019 \\
\hline Union time (Wks) & $12.4 \pm 0.51$ & $10.7 \pm 0.14$ & 0.0001 \\
\hline T reatment cost( US dollar) & $31.04 \pm 12.16$ & $50.68 \pm 11.70$ & 0.0001 \\
\hline
\end{tabular}

\section{Hospital stay and treatment cost}

Children in group B were discharged from hospital with average duration of $6.56 \pm 2.75$ days as compared to $3.32 \pm 1.4$ days in group $A(p=0.000)$. Hospital cost was more for children with fracture managed with Rush pins (US dollars $50.68 \pm 11.70$ ) group $B$ vs. $31.04 \pm 12.16$ group $A, p=0.000$ ). (Table $3)$. Increased hospital cost in group $B$ can be attributed to longer hospital stay which ranges from 3 to 14 days as many patients in our teaching hospital come from far and remote distance from where it is not only expensive but also difficult for coming to hospital for removal of sutures. So they preferred longer hospital stay till sutures were removed.

\section{Flynn grading}

Final outcome at the end of follow up was evaluated according to Flynn grading [1]. Table 4 shows individually and overall group $B$ have superior outcome as compare to group A. 19/25 (76\%) had excellent, 5/25 (20\%) had satisfactory and 1/25 (4\%) had poor result in children in group $\mathrm{B}$ as compare to $4 / 24(17 \%)$ excellent, $11 / 24(49 \%)$ satisfactory and $9 / 24(44 \%)$ poor in group $A(p=0.000)$.

\section{Complications}

In group $A, 3$ patients had plaster sores at perineal area which recovered with dressing and antibiotics; 1 child was had broken and loosened hip spica on $2^{\text {nd }}$ week (Figure 1D) and needed reapplication of spica; 4 children had increased angular deformity or overlapping but within acceptable range on $2^{\text {nd }}$ weeks of follow up.

Table 4: Flynn's Grading (2001, JPO).

\begin{tabular}{|lccc|}
\hline \multicolumn{1}{|c}{ Flynn's Grading } & Excellent & Satisfactory & Poor \\
\hline Limb length discrepancy & $<\mathrm{lcm}$ & $>$ lcm & $>2 \mathrm{~cm}$ \\
& $11(45 \%) / 22(88 \%)$ & $6(25 \%) / 3(12 \%)$ & $7(30 \%) / 0$ \\
Misalignm ent & $<5^{\circ}$ & $<10^{\circ}$ & $>10^{\circ}$ \\
& $5(20 \%) / 22(88 \%)$ & $9(38 \%) / 2(8 \%)$ & $10(42 \%) / 1(4 \%)$ \\
Complications & None & Minor and resolved & Major and lasting \\
& $20(83 \%) / 23(92 \%)$ & $4(17 \%) / 2(8 \%)$ & $0 / 0$ \\
Over all result & $4(17 \%) / 19(76 \%)$ & $11(49 \%) 5(20 \%)$ & $9(44 \%) / 1(4 \%)$ \\
\hline
\end{tabular}

In group B, 2 children had complications related with long protruded Rush pin at entry site. One child presented with pin tract infection on $7^{\text {th }}$ day of surgery which recovered after trimming of protruded part; another child presented with bursitis after one year which recovered after removal of Rush pins. One patient had lost anterio-posterior alignment on $6^{\text {th }}$ week follow up. In one child, penetration of posterior cortex of base of neck was identified in subsequent follow up. Rush pin was removed on $6^{\text {th }}$ month and did not show any changes of avascular necrosis till one and half years of follow up. Another patient had penetration of greater trochanter and he also had no limb length discrepancy.

\section{Discussion}

Staheli et al [6] defined the ideal treatment of femoral shaft fractures in children as one that controls alignment and length, does not compress or elevate the extremity excessively, is comfortable for the child and convenient for the family and causes the least negative psychological impact possible. Immediate spica casting or skeletal traction and application of a cast is common method for treatment of diaphyseal femoral fractures in children and young adolescents and surgical intervention is indicated in open fractures, multi-trauma, concomitant head injuries, burns and neuromuscular wounding. However, Hughes BF et al [7] have reported psychosocial and economic effects of spica cast immobilization on children and their families by and many studies advocate early fixation of femur fracture because complications inherent in conservative treatment, such as malunion and shortening, cast intolerance, financial factors and increased hospitalization can be decreased by surgery. Among other operative methods, flexible intramedulary nail has been used increasingly due to its simplicity and characteristics of load sharing internal splint which maintains length and 
alignment of the limb until bridging callus is formed and spares the risk of damaging the physis or the blood supply to the capital femoral epiphysis with proper surgical technique.

Torsional stability depends upon divergence of the rods in the proximal metaphysis and resistance to sagittal and cornal bending results from spreading of the prebent rods through the diaphysis, size of the rod and material properties of the rod. Micro motion confirmed by elasticity of fixation promotes early callus formation. There are no clinical study comparing efficacy of titanium elastic nail with stainless steel nail like Enders nail, Rush pins. The Young modulus of stainless steel is nearly double that of titanium (approximately $200 \mathrm{GPa}$ versus approximately $110 \mathrm{GPa}$ ), making it a much stiffer material with less elastic properties. Lee et al [8] demonstrated that Ender nail fixation of simulated femur fractures maintained fracture length and rotational control with weight bearing of up to $40 \%$ of body weight, even in presence of comminution. Where as Mahar et al [9] reported that the titanium implants provided greater stability in resisting torsional loading and axial compression in both transverse and comminuted fractures in biomechanical comparative study with stainless steel nails. Besides elastic property, retrogradely passed adequate size crossed Rush pins offer all the advantages of closed reduction technique and inernal fixation with flexible intramedullary nails. Excellent clinical results using stainless steel flexible nails have been reported for both stable and unstable femur fracture in children. Rathjen KE et al [10] assume that the stiffer properties of a stainless steel implant should confer greater fracture stability, especially in the setting of an unstable fracture pattern.

Eric et al [11] have demonstrated 118 patients with use of titanium elastic nails as compared with stainless steel elastic nails and noted the malunion rate was significantly higher in the titanium group (23.2\%; thirteen of fifty-six) than in the stainless steel group (6.3\%; three of forty-eight). The risk of malunion was nearly four times higher in the titanium group than in the stainless steel (Rush pin) group. The present study showed that the clinical outcome of stainless steel nail (Rush pin) fixation was superior to that of titanium nail fixation because the former was associated with a significantly decreased rate of malunion. Rush pins are stiffer than titanium nails, which may be beneficial for preventing angular malunions following pediatric femoral fractures.

Cramer et al [12], 10 prospectively evaluated 57 femoral shaft fractures in children treated with Ender rods, 21 of which were either spiral fractures or comminuted. Although the results were not stratified according to fracture stability, the authors noted no clinically significant leg length discrepancy or malunion. Four patients did demonstrate radiographic angular deformities of less than 15 degrees deviation at final follow-up.

Simanovsky $N$ et al [13] defined that the flexible intramedullary nails can be an attractive and safe treatment options in children aged 3-5 yrs for femoral shaft fracture and should be brought up and discussed with parents.

Another advantage of Rush pin would be readily availability according to the size of pediatric femoral bone length, no need to cut and bend at the entry site of insertion. The available pre bent Rush pins are easily removable and less irritable soft tissue. Pre bent Rush pins are cheap, universally available and can be manufactured locally.

This study had a prospective design, and used a convenience sample, which were limitations of the study. The different characteristics of the two groups of patients were also a limitation. Nonetheless, this study points towards the important that femoral shaft fractures in children can be better treated with surgery. This is a proper scenario within which a randomized controlled trial could be developed in order to obtain reliable answers, without bias.

Conclusion: Intra-medullary crossed Rush pinning is an effective method of management of paediatric diaphyseal femur fracture fixation as compare to primary hip spica in terms of early ambulation, return to normal activities and school earlier. Gives a predictable clinical pathway and reduces periods of traction and occupancy of hospital beds.

\section{References}

1. Flynn JM, Schwend RM. Management of pediatric femoral shaft fractures. J Am Acad Orthop Surg. 2004; 12(5):347-59.

2. Kirby RM, Winquist RA, Hansen ST Jr. Femoral shaft fractures in adolescents: a comparison between traction plus cast treatment and closed intramedullary nailing. J Pediatr Orthop. 1981;1(2):193-7.

3. Mann DC, Weddington J, Davenport K. Closed Ender nailing of femoral shaft fractures in adolescents. J Pediatr Orthop. $1986 ; 6(6): 651-5$

4. Ligier JN, Metaizeau JP, Prévot J, Lascombes P. Elastic stable intramedullary mailing of femoral shaft fractures in children. $J$ Bone Joint Surg Br. 1988;70(1):74-77.

5. Nascimento FP, Santili C, Akkari M, et al. Short hospitalization period with elastic stable intramedullary nails in the treatment of femoral shaft fractures in school children. J Child Orthop. 2010;4(1):53-60.

6. Staheli LT, Sheridan GW. Early spica cast management of femoral shaft fractures in young children. A technique utilizing bilateral fixed skin traction. Clin Orthop Relat Res. 1977;(126):162-6.

7. Hughes BF, spousaller PD, Thorpson JD: Pediatric femur fracture: Effect of spica cast treatment on family and community. Pediatr. Orthop. 1994;15 : 457-460.

8. Lee SS, Mahar AT, Newton PO. Ender nail fixation of pediatric femur fractures: a biomechanical analysis. J Pediatr Orthop $2001 ; 21: 442-445$. 
9. Fricka, Kevin B. MD; Mahar, Andrew T. MS; Lee, Steven S. MD; Newton, Peter O.MD.Biomechanical Analysis of Antegrade and Retrograde Flexible Intramedullary Nail Fixation of Pediatric Femoral Fractures Using a Synthetic Bone Model. Journal of Pediatric Orthopaedics. 2004;24(2):167-171.

10. Rathjen KE, Riccio AI, De La Garza D: Stainless steel flexible intramedullary fixation of unstable femoral shaft fractures in children. J Pediatr Orthop. 2007; 27:432-41.

11. Wall EJ, Jain V, Vora V, Mehlman CT, Crawford $A H$. Complications of titanium and stainless steel elastic nail fixation of pediatric femoral fractures. J Bone Joint Surg Am. 2008; 90(6):1305-13.

12. Cramer KE, Tornetta $\mathrm{P}$ 3rd, Spero CR, Alter S, Miraliakbar H, Teefey J. Ender rod fixation of femoral shaft fractures in children. Clin Orthop. 2000; 376:119-23.

13. Simanovsky N, Porat S, Simanovsky N, Eylon S. Close reduction and intramedullary flexible titanium nails fixation of femoral shaft fractures in children under 5 years of age. $J$ Pediatr Orthop B. 2006; 15(4):293-7. 